Case report

\title{
Experience of using secukinumab in treatment of severe refractory psoriasis: a clinical case.
}

\author{
Nikolay V. Kungurov ${ }^{1}$, Yulia V. Keniksfest ${ }^{1}$, Muza M. Kokhan ${ }^{1}$, Tatyana A. Syrneva ${ }^{2}$, Elena V. Grishaeva ${ }^{1}$ \\ ${ }^{1}$ Ural Research Institute of Dermatovenereology and Immunopathology, Yekaterinburg, Russia \\ ${ }^{2}$ Ministry of Health of the Sverdlovsk region, Yekaterinburg, Russia
}

Received 27 March 2019, Accepted 14 May 2019

(C) 2019, Kungurov N.V., Keniksfest Y.V., Kokhan M.M., Syrneva T.A., Grishaeva E.V.

(C) 2019, Russian Open Medical Journal

Abstract: In this article we present a clinical case of a patient with severe psoriasis. We assessed efficacy and safety of secukinumab therapy with 88 weeks follow-up.

Keywords: psoriasis, systemic therapy, genetically engineered biological therapy, quality of life.

Cite as Kungurov NV, Keniksfest YV, Kokhan MM, Syrneva TA, Grishaeva EV. Experience of using secukinumab in treatment of severe refractory psoriasis: a clinical case. Russian Open Medical Journal 2019; 8: e0209.

Correspondence to Yulia V. Keniksfest. Address: 8, Shcherbakova str., Yekaterinburg, 620076, Russia. Tel.: +73432189561. E-mail: keniksfest@mail.ru.

\section{Introduction}

An increased incidence of psoriasis, including young population, increased prevalence of severe (erythroderma, pustular psoriasis, psoriatic arthritis) and refractory (to various types of treatment, including cytostatic and immunosuppressive therapy) cases, along with increased frequency of long term and permanent disability in such patients are observed in Russia in recent years [1]. According to global European study EUROPSO a significant proportion of all patients with psoriasis have severe cases of this condition: in European countries $12.0-27.0 \%$ of all surveyed patients perceive it as severe, and $51.0 \%$ of patients report a significantly impaired psoriasis-related quality of life [2, 3]. Improving therapy in psoriasis patients remains an important medical and social problems due to a steadily high incidence of this skin condition in Russian Federation. In recent years severe and disabling cases become more common, torpidity of psoriasis and lack of efficiency of standard therapeutic approaches are observed, while the incidence of iatrogenic complications increases $[4,5]$.

Among all hospitalizations to the clinic of Ural Research Institute of Dermatovenereology and Immunopathology (Yekaterinburg, Russia) psoriasis patients made up to 19.8-42.0\% cases in different time periods, while an absolute number of hospitalized patients increased 2.9 times during 2000-2018 period. Studies have shown that hospitalized patients with severe psoriasis and high Psoriasis Area and Severity Index (PASI) scores suffer from extremely decreased disease-related quality of life. The most pronounced negative influence of disease on quality of life was observed in patients with psoriatic erythroderma and psoriatic arthritis [2]

General approaches to psoriasis therapy with specifics of clinical manifestations, severity and comorbidities taken into account are presented in Russian clinical recommendations, guidelines on psoriasis treatment of various European countries and European academy of dermatology and venereology [3, 6].

Introduction of genetically engineered biological drugs (GEBD) to clinical practice during the last decade has lead to a significant paradigm shift in treatment of psoriasis and psoriatic arthritis. However, standards established in Russian Federation today do not include all modern methods of diagnostics and treatment of chronic skin conditions, including psoriasis. For example, healthcare standard for psoriasis patients (L40) does not mention GEBD, and healthcare standard for patients with psoriatic arthritis (L40.5) includes only infliximab, because other GEBDs were not registered for use in Russia at that point $[7,8]$. However, the list of drugs approved for genetically engineered biological therapy (GEBT) of psoriasis is quite big today [4-6, 9].

For several years a comprehensive evaluation of efficacy, safety and outcomes of therapy in patients with psoriasis and psoriatic arthritis is being conducted as part of international prospective observational study PSOLAR (Psoriasis Longitudinal Assessment and Registry), which includes more than 12 thousand patients with psoriasis receiving systemic therapy, including GEBT. Studies have shown that GEBD are effective at early stages of the disease, but a reduction of clinical response is possible over time or even after modification of therapy, which eventually leads to a pause in treatment or to a switch for GEBT with other mode of action [4, 5, 9]. In Russian clinical practice first-line treatment of psoriasis and psoriatic arthritis usually includes anti-TNF $\alpha$ drugs (infliximab, adalimumab, etanercept), and ustekinumab treatment is usually administered after their effect is lost [5-7].

In Ural Research Institute of Dermatovenereology and Immunopathology treatment of patients with severe refractory psoriasis and psoriatic arthritis using GEBD began in 2006, and more than 2,200 injections of biologicals were performed during 10 -year period. Since 2006 residents of Sverdlovsk region receive GEBT covered by high-technology medical care (HTMC) program 
within compulsory health insurance system (CHI). Moreover, since 2014 order of Ministry of Health of Sverdlovsk Oblast enacts additional measures and schemes of medical treatment including genetically-engineered pharmaceuticals for patients with severe, disseminated and torpid cases of psoriasis. For this, clinicalstatistical groups (CSG) were defined to provide specialized outpatient medical care with specific GEBDs, their regimens and costs taken into account $[10,11]$.

Federal clinical recommendations which were reviewed by independent experts and discussed by workgroup members (council of experts) of Russian society of dermatovenereologists and cosmetologists contain contemporary point of view (consensus) of experts, clinical trial data and reviews of published meta-analyses on etiology, pathogenesis, clinical presentation, systemic and topical therapy and prevention of skin diseases, ranged by evidence strength rating (from $A$ to $D$ ). Clinical recommendations are renewed every 3 years and expanded with drugs newly registered in Russia, including the ones used for GEBT. But until 2019 legal framework implied departmental control over adherence only to standards of medical care, which led to some difficulties in providing specialized care to patients with chronic skin conditions [6].

A Federal law «On amendments to article 40 of Federal law "On compulsory health insurance in the Russian Federation» and Federal law «On the Fundamentals of Protection of the Public Health in the Russian Federation" related to clinical recommendations» (December, 25; №489-FZ) was passed by State Duma on December, 19 of 2018 and ratified by Federation Council on December, 21 of 2018. This Federal law is active since January, 1 of 2019 and will facilitate a creation of complex of therapeutic measures for patients with chronic skin conditions, including psoriasis and psoriatic arthritis, including the ones who need GEBT.

Since 2016 a joint work with territorial $\mathrm{CHI}$ fund is being conducted to change and expand CSGs (subgroups) with newly registered drugs and new indications for already registered GEBD, which is going to improve extents of specialized medical care for patients with severe psoriasis refractory to traditional and reserve modes of treatment $[10,11]$.

In July 2016 a new GEBD secukinumab («Cosentyx») was registered in Russian Federation. It is a fully human antibody immunoglobulin G1 (IgG1), which acts as a targeted inhibitor of proinflammatory cytokine interleukin-17A (IL-17A), decreases its interaction with IL-17 receptors, which are expressed by activated lymphocytes, keratinocytes and synoviocytes defining the development of psoriasis, therefore possessing a selective activity towards the key cause of psoriasis and psoriatic arthritis symptoms [12-14]. Clinical trials of secukinumab have shown that it leads to a rapid clinical response with decrease in inflammation severity and infiltration of psoriatic lesions by third week of treatment; using "Cosentyx» for 5 years in patients with psoriasis leads to "clean» or "almost clean» skin in overwhelming majority of patients with PASI score of 90 in 8 patients out of 10 and PASI score of 100 in 4 patients out of $10[13,14]$. "Cosentyx" has a favorable safety profile for patients with psoriasis or psoriatic arthritis both in clinical trials and in routine clinical practice.

In this article we present a clinical case of effective therapy with IL-17A blocker (secukinumab) in a patient with severe refractory psoriasis and psoriatic arthritis.

\section{Clinical case}

Patient A., born in 1974, served in military, afflicted with psoriasis for over than 25 years. Associates the onset of psoriasis with stress while being in a combat zone, where he suffered an injury with contusion. Family history is negative. First lesions occurred on scalp, then fingernails began to change. During the first 5 years of disease course it affected skin of upper and lower extremities and torso. Patient received treatment prescribed by dermatologist (vitamins, topical glucocorticoids, PUVA therapy) with brief positive results (Editor's note: PUVA is an ultraviolet light therapy treatment using the sensitizing effects of the drug psoralen). Since 2000 there was erythoderma with total involvement of fingernails and pain in interphalangeal joints, which was later accompanied by pain in cervical and thoracic spine. Psoriatic arthritis (distal interphalangeal arthritis, psoriatic spondylitis) was diagnosed by a rheumatologist. Since 2005 skin condition took a continuously relapsing course, and patient received treatment in clinic of Ural Research Institute of Dermatovenereology and Immunopathology (up to 4 times per year), where all treatment modalities were used: PUVA therapy with deterioration after more than 95 procedures during 1998-2005, cytostatic therapy with 15-25 mg methotrexate for more than 5 years with toxic hepatitis as a result, immunosuppresive therapy with $5 \mathrm{mg} / \mathrm{kg}$ cyclosporin A for 1.5 years with a sharp loss of efficacy, acitretin (synthetic analogue of vitamin A) therapy with loss of efficacy. Since 2005 because of dermatologic manifestations and severe involvement of joints patient was unable to work, had to leave his job, had a decreased quality of life with signs of depression. Patient was acknowledged to be disabled (II group of disability).

Taking into account severity of clinical manifestations, severity of skin and joint involvement, resistance to previously used therapies, including cytostatic, immunosuppressive and PUVA therapy, in 2007 patient was prescribed with GEBT using $5 \mathrm{mg} / \mathrm{kg}$ tumor necrosis factor alpha inhibitor infliximab. PASI score was 56.2 before initiation of therapy. Therapy start was well tolerated, and positive results were observed concerning skin manifestations: PASI score was equal to 90 at 5th infusion, and patient noticed improvement of his joints condition (pain decreased, while mobility improved). Infliximab therapy was continued up to 2014, but then there was a rapid decrease in therapeutic efficacy with appearance of disseminated lesions and joint pain. Cytostatic therapy with methotrexate was added, but after 3rd 15 mg injection liver enzyme activity elevated more than 5 times, so the cytostatic therapy had to be cancelled. During another scheduled infliximab injection there was an infusion reaction. It was decided to stop infliximab therapy. Twelve weeks after cancellation of GEBT there was a pronounced deterioration in skin and joint condition. Immunosuppressive therapy with $5 \mathrm{mg} / \mathrm{kg}$ cyclosporin A was started, which allowed to stabilize psoriasis for 2 months. Then there was skin condition deterioration once again with development of erythroderma, and patient started to take systemic glucocorticosteroids ( $40 \mathrm{mg} /$ day) as prescribed by a local dermatologist. Patient suffered a decreased quality of life, became depressed and started to use alcohol, divorced and had to be financially supported by his mother, who was his caretaker. A collective decision to start second-line GEBT with ustekinumab was made. Therapy was started in May 2015, and PASI score prior to first administration of ustekinumab was equal to 49.6. During GEBT with ustekinumab there was a positive dynamic for skin condition (severity of skin manifestations decreased) with PASI score of 75 and joint condition (decreased pain - no need for nonsteroidal anti-inflammatory drugs and systemic 
glucocorticosteroids, improved mobility). Treatment was well tolerated, there were no adverse events. However, after GEBD infusion in March, 2016 there was no significant improvement, and patient noticed new lesions, edema and skin peeling. Patient underwent workup and treatment in hospital of Ural Research Institute of Dermatovenereology and Immunopathology in April, 2016 to adjust therapy (combined therapy with PUVA and baths with «Ammifurin» solutions, 10 sessions). Patient was discharged with improved skin condition. Two weeks after discharge his skin condition has exacerbated with many new lesions and itching. Betamethasone injection had no effect, condition has progressed with many new lesions, chills and itching. Ustekinumab therapy was started again with interval between infusions shortened to 8 weeks, combined with acitretin $50 \mathrm{mg}$ per day. All the while dermatosis had a steady course without signs of clinical remission, and PASI score lingered at 39.6-42.3. Ex consilio a decision was made to cancel ustekinumab and start alternative regimen with secukinumab, which at this point was already registered in Russia. However, because there was no possibility to supply the patient with this drug (bureaucratic factors, ineffective coordination between officials), therapy could not be started. Since December, 2016 skin condition deteriorated, and soon there was articular pain and edema along with new skin lesions. In January, 2017 patient underwent acute respiratory viral infection and local internist prescribed him doxycycline, which lead to further deterioration of skin condition with appearance of new lesions, stark hyperemia and severe infiltration. Antibacterial drug was stopped. He was hospitalized in clinic of Ural Research Institute of Dermatovenereology and Immunopathology with erythroderma and PASI score of 66.7. He received combined therapy with infusions and systemic glucocorticosteroids, hepatic protectors, PUVA baths with Ammi majoris furocumarins - 12 sessions, and was discharged with improvement of skin condition (regression of $50 \%$ of lesions). Remission did not last. Seven days after discharge skin condition has exacerbated (without any known factor) with erythroderma and body temperature elevated up to $38^{\circ} \mathrm{C}$. Patient was immobile due to severe joint involvement, could not leave his bed, refused to eat. At local facility he was prescribed with dexamethasone $8 \mathrm{mg} \mathrm{i} / \mathrm{m}$, received 3 injections, while topically he used vaseline. After consultation in Ural Research Institute of Dermatovenereology and Immunopathology he once again began to take acitretin $75 \mathrm{mg}$ per day for 3 days, then $50 \mathrm{mg}$ per day, and there was an improvement of his skin condition. Patient's overall condition improved, he became mobile. During all this period he sent letters to healthcare management offices and territorial fund of compulsory health insurance in order to be supplied with GEBD secukinumab. He received formal answers which stated that this modality of healthcare is inaccessible. Desperate, the patient took this matter to a court and wrote a letter to President of Russian Federation. In May, 2017 he again received treatment in clinic ща Ural Research Institute of Dermatovenereology and Immunopathology without improvement in skin condition (Figure 1). Patient's quality of life has extremely deteriorated, he began to express suicidal thoughts and ideas of violence towards officials who hindered his access to new treatment methods.

Considering severity of skin condition, its unresponsiveness to previously tried traditional methods of treatment and resistance to backup therapy (infliximab and ustekinumab), treatment with GEBD secukinumab was started as a part of sponsored clinical trial in Ural Research Institute of Dermatovenereology and Immunopathology. One week after the first dose a significant clinical improvement was observed (Figure 2). After initial course of therapy skin lesions regressed by more than $70 \%$ (Figure 3). This treatment was continued. To this day, patient continues to receive GEBD secukinumab in a standard regimen; overall, he received 26 infusions for 88 weeks of treatment (Figure 4). PASI score of 90 was reached. Patient's quality of life has fully recovered and he returned to work activity.

Good tolerability of secukinumab was observed, there were no adverse events; laboratory control with complete blood count and blood chemistry demonstrated no outstanding values during the course of treatment.

\section{Discussion}

Severe cases of psoriasis and psoriatic arthritis with continuously relapsing course, critical impairment of quality of life and long term disability in patients of young and middle age are not uncommon in routine clinical practice. Such patients are treated with systemic drugs with pathogenetically driven mode of action, possessing anti-inflammatory and immunosuppressive properties: phototherapy and its combined varieties, photochemotherapy, methotrexate, synthetic retinoids, cyclosporin and GEBD $[3,4]$. However, even after all available treatment options are used, there are still some patients in whom psoriasis remains uncontrollable.

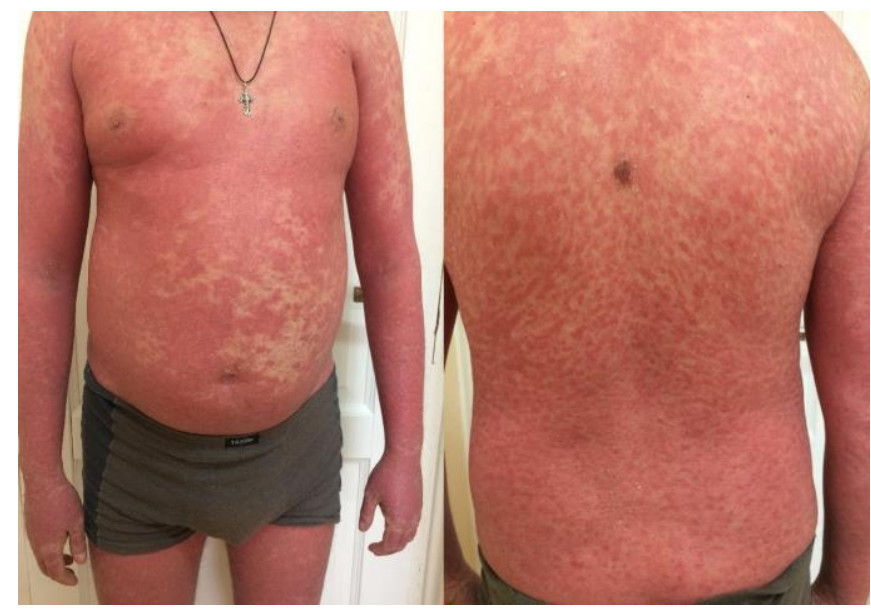

Figure 1. Patient A: before treatment (May, 2017).

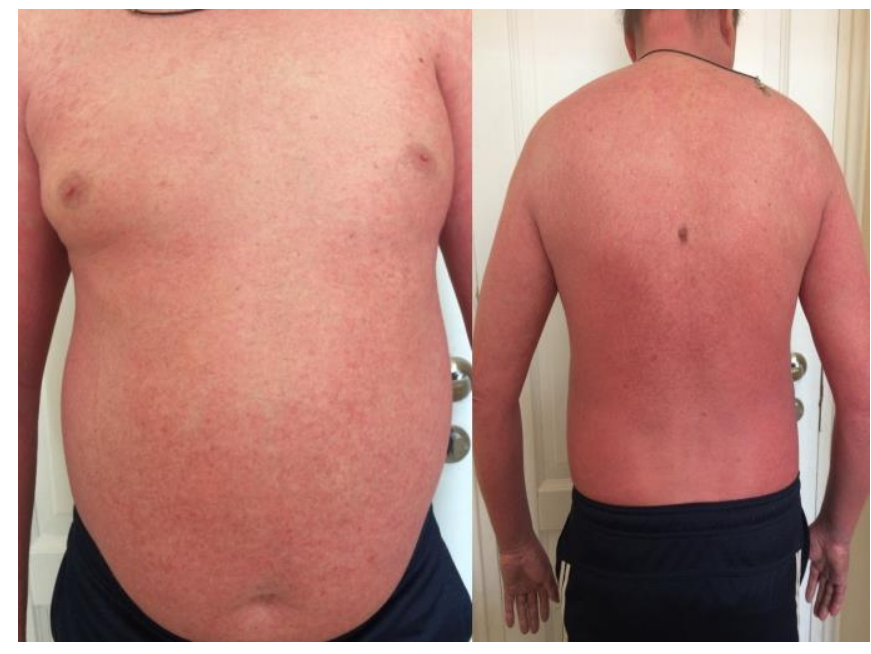

Figure 2. Patient A: 7 days after initial drug infusion. 


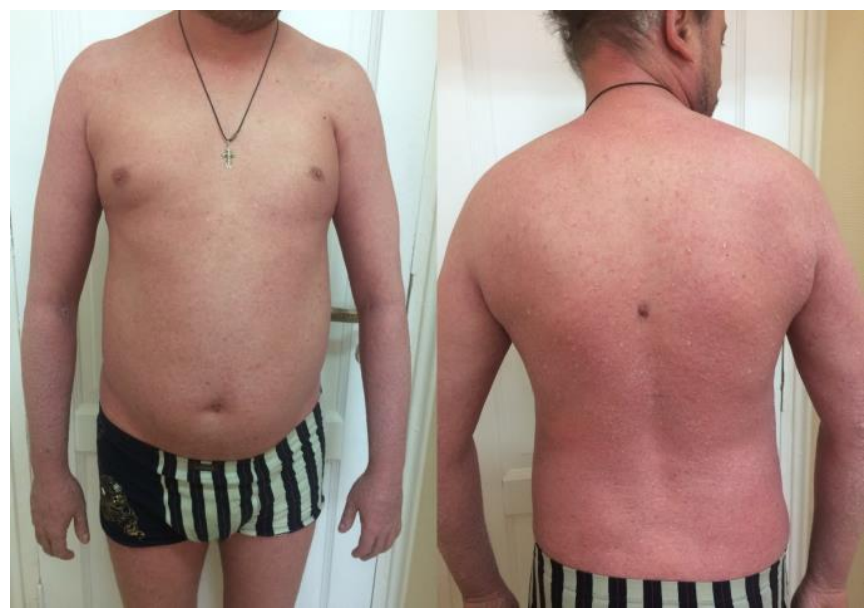

Figure 3. Patient A: after the initial course of treatment.

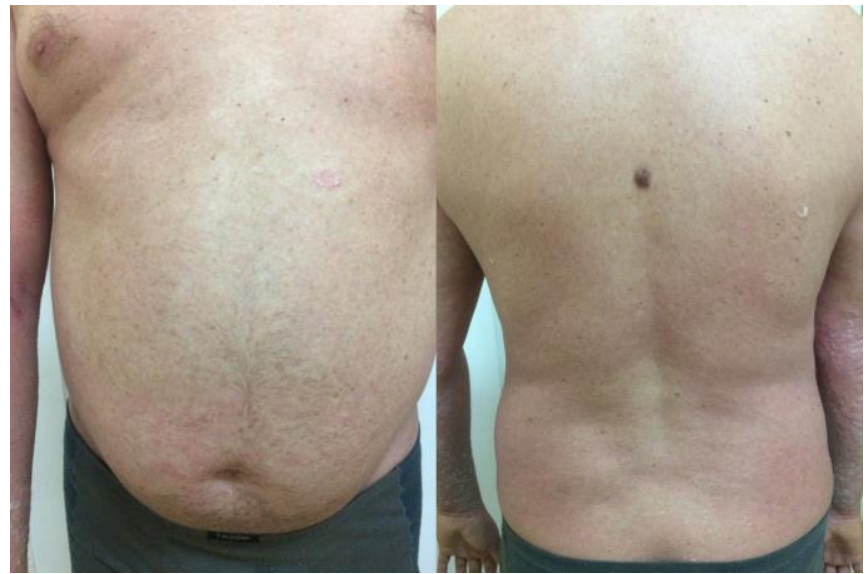

Figure 4. Patient A: after 88 weeks of treatment.

New targeted drugs with high efficacy and good safety profile, such as secukinumab, a IL-17A-blocker, looks promising for this cohort of patients, and it is very important for dermatovenereologists to accumulate and synthesize their own clinical experience with such drugs.

\section{Conclusion}

Overall, this experience of using GEBD secukinumab in real clinical practice has demonstrated good results in a patient with severe case of psoriasis, so that prescribed pathogeneticallyoriented therapy has allowed not only to achieve clinical remission and to mitigate symptoms, but also to significantly improve patients's quality of life.

\section{Conflict of Interests: none declared.}

\section{Ethical approval}

All procedures performed in studies involving human participants were in accordance with the ethical standards of the institutional research committee and with the 1964 Helsinki declaration and its later amendments or comparable ethical standards.

\section{References}

1. Kubanova AA, Kubanov AA, Melekhina LE, Bogdanova EV. Dermatovenereologic healthcare delivery in Russian Federation. Incidence of sexually transmitted infections and skin disorders, 20132015. Vestnik Dermatologii i Venerologii 2016; (3): 12-28. Russian. https://elibrary.ru/item.asp?id=26415064.

2. Grishaeva EV, Kokhan MM, Keniksfest YuV, Zasadkevich YuM, Tolstaya Al. Positive dynamics of the quality of life of patients with psoriasis, as an indicator of the effectiveness of the hospital phase of treatment. Sovremennye Problemy Dermatovenerologii, Immunologii i Vrachebnoj Kosmetologii 2010; 5(5): 36-41. Russian. https://elibrary.ru/item.asp?id=15267024.

3. Nast A, Gisondi P, Ormerod AD, Saiag P, Smith C, Spuls PI. European S3-Guidelines on the systemic treatment of psoriasis vulgaris--Update 2015--Short version--EDF in cooperation with EADV and IPC. J Eur Acad Dermatol Venereol 2015; 29(12): 2277-2294. https://doi.org/10.1111/jdv.13354

4. Kungurov NV, Zilberberg NV, Kokhan MM, Keniksfest YuV, Grishayeva EV. Experience of using the drug secukinumab in the treatment of severe resistant psoriasis. Lechaschi Vrach Journal 2017; (11): 17. Russian. https://elibrary.ru/item.asp?id=30563501.

5. Kungurov NV, Kohan MM, Kenicksfest YV. Biological therapy of patients with severe psoriasis. Vestnik Dermatologii $i$ Venerologii 2012; (4): 91-95. Russian. https://elibrary.ru/item.asp?id=18208294.

6. Federal clinical guidelines for the management of patients with psoriasis. Moscow, Russia, 2015; 59 p. Russian. www.cnikvi.ru/docs/clinic recs/bolezni-kozhi-i-pridatkovkozhi/Псориаз.doc

7. Order of the Ministry of Healthcare of Russia of 30.05.2006 N 433 “On approval of the standard of care for patients with psoriasis". Russian. http://www.consultant.ru/cons/cgi/online.cgi?req=doc\&base=EXP\&n= 412556\#05495190276706772.

8. Order of the Ministry of Healthcare and Social Development of the Russian Federation of 12.18.2007 N 776 "On approval of the standard of care for patients with psoriatic arthritis". Russian. http://www.consultant.ru/cons/cgi/online.cgi?req=doc;base=EXP; $n=4$ 12975\#03218235095198392.

9. Kungurov NV, Keniksfest YV, Filimonkova NN. Immunosupressive and biological therapy for patients with severe psoriasis. Journal of Ural Medical Academic Science 2011; (2-2(35)): 35-36. Russian. https://elibrary.ru/item.asp?id=20226365.

10. Order of the Ministry of Health of the Sverdlovsk region and TFOMS of the Sverdlovsk region of 23.01.2015, №73-p / 17 (as amended on 04.19.2016, №591-p / 178, of 15.08.2017, №1380-p / 363) "On the formation and maintenance of territorial registers of patients with certain diseases requiring the use of expensive drugs". Russian.

11. Order of the Ministry of Health of the Sverdlovsk region of June 27, 2014 No. 819-p "On Amendments to the Order of the Ministry of Health of the Sverdlovsk Region of September 23, 2009 No. 900-p "On Improving the Organization of Medical Care to Patients in DayHospital"', Appendix 49 "The scheme of medical care for patients with severe, common, torpidly flowing forms of psoriasis using genetically engineered pharmaceuticals". Russian. http://www.tfoms.eburg.ru/upload/iblock/113/pr 2014.06.27 819-p.pdf.

12. Thaçi D, Blauvelt A, Reich K, Tsai TF, Vanaclocha F, Kingo K, et al. Secukinumab is superior to ustekinumab in clearing skin of subjects with moderate to severe plaque psoriasis: CLEAR, a randomized controlled trial. J Am Acad Dermatol 2015; 73(3): 400-409. https://doi.org/10.1016/j.jaad.2015.05.013.

13. Mease PJ, Mclnnes IB, Kirkham B, Kavanaugh A, Rahman P, van der Heijde $D$, et al. Secukinumab Inhibition of Interleukin-17A in Patients with Psoriatic Arthritis. N Engl J Med 2015; 373(14): 1329-1339. https://doi.org/10.1056/NEJMoa1412679.

14. McInnes IB, Mease PJ, Kirkham B, Kavanaugh A, Ritchlin CT, Rahman P, et al. Secukinumab, a human anti-interleukin-17A monoclonal 
antibody, in patients with psoriatic arthritis (FUTURE 2): a randomised, double-blind, placebo-controlled, phase 3 trial. Lancet 2015; 386(9999): 1137-1146. https://doi.org/10.1016/S0140-6736(15)61134$\underline{5}$.

Authors:

Nikolay V. Kungurov - MD, DSc, Professor, Director of Ural Research Institute of Dermatovenereology and Immunopathology, Yekaterinburg, Russia. https://orcid.org/0000-0002-4134-047X.

Yulia V. Keniksfest - MD, DSc, Head of the Department of Chronic Dermatosis for Adults Ural Research Institute of Dermatovenereology and Immunopathology, Yekaterinburg, Russia. https://orcid.org/0000-00018431-5664.

Muza M. Kokhan - MD, DSc, Professor, Head of the Scientific Clinical Department of Dermatology, Ural Research Institute of Dermatovenereology and Immunopathology, Yekaterinburg, Russia. https://orcid.org/0000-0001-6353-6644.

Tatyana A. Syrneva - MD, DSc, Professor, Chief Freelance Dermatovenerologist of the Ministry of Health of the Sverdlovsk region, Yekaterinburg, Russia. https://orcid.org/0000-0002-1062-9975.

Elena V. Grishaeva - PhD, Head of Clinical Department, Ural Research Institute of Dermatovenereology and Immunopathology, Yekaterinburg, Russia. https://orcid.org/0000-0001-9891-1942. 